\title{
O COTIDIANO DE TRABALHO NA ESTRATÉGIA SAÚDE DA FAMÍLIA: ENTRE O REAL E O IDEAL
}

\section{THE DAILY LIFE OF FAMILY HEALTH STRATEGY TEAMS: BETWEEN THE REAL AND THE IDEAL}

\section{LO COTIDIANO DEL TRABAJO DE LA ESTRATEGÍA SALUD DE LA FAMILIA: ENTRE LO REAL Y LO IDEAL}

\author{
Juliana Ferreira da Silva ${ }^{1}$, Deborah Franscielle da Fonseca ${ }^{2}$, Joseane da Silva ${ }^{3}$, Selma Maria da Fonseca Viegas ${ }^{4}$, Fernada Moura
} Lanza $^{5}$.

\begin{abstract}
RESUMO
Objetivo: Analisar o cotidiano do trabalho de equipes da Estratégia Saúde da Família. Método: Estudo de caso de abordagem qualitativa, realizado em 10 equipes da Estratégia Saúde da Família em um município de Minas Gerais com 39 profissionais. A coleta de dados ocorreu por meio de entrevista semiestruturada. Utilizou-se a análise de conteúdo na modalidade temática. Resultados: $\mathrm{O}$ trabalho em saúde, no cenário estudado, está fragmentado, reproduz o modelo médico-centrado e restringe o escopo de ações da Estratégia Saúde da Família. Destaca-se o vínculo, as ações orientadas à comunidade e formação profissional voltada para as novas necessidades do trabalho em saúde como elementos que podem qualificar o atendimento na Atenção Primária à Saúde. Conclusão: Apesar da implantação da Estratégia Saúde da Família, no município estudado, há quase duas décadas, sua função de reestruturadora do modelo de atenção ainda apresenta fragilidades. Os agentes do trabalho reconhecem a necessidade de mudança, mas mantêm articulação das ações cotidianas sem transformações de ordens simbólicas. Há evidências de práticas exitosas que, se incorporadas às práticas de atenção à saúde, contribuirão para a qualificação da assistência e mudança do modelo de atenção à saúde.
\end{abstract}

Descritores: Estratégia Saúde da Família; Atenção Primária à Saúde; Sistema Único de Saúde.

\begin{abstract}
Objective: To analyze the daily routine of the Family Health Strategy team. Method: Case study of a qualitative approach carried out with 10 teams of the Family Health Strategy in a municipality of Minas Gerais, with 39 health professionals. Specific data was collected through a semi-structured interview. Content analysis was used in the theme mode. Results: The health work in the studied settings is fragmented. It reproduces the medical-centered model and restricts the range of actions of the Family Health Strategy. Bonding is highlighted, as well as community-oriented actions and professional training focused on the new needs of this health work as elements that can qualify and enhance the attending in Primary Health Care. Conclusion: Despite the implantation of the Family Health Strategy in the studied municipality almost two decades ago, its role of restructuring the attention model still presents flaws and weaknesses. Labor agents recognize the need for change, but maintain the articulation of daily actions without any symbolic changes. There is evidence of successful practices that are incorporated into health care, contributing to the qualification of health assistance and changes of the health care model.
\end{abstract}

Descriptors: Family Health Strategy; Primary Health Care; Unified Health System; Biomedical Technology.

\section{RESUMEN}

Objetivo: Analizar lo cotidiano del trabajo en los equipos de estrategia de salud de la familia. Método: Estudio de caso de abordaje cualitativo realizado en 10 equipos de la estratégia de salud de la familia de un municipio de Minas Gerais, con 39 profesionales. La recolección de datos fue por medio de entrevistas semi estructuradas. Se utilizó análisis del contenido en la modalidad temática. Resultados: El trabajo en salud del escenario estudiado está fragmentado, reproduce el modelo médico-centrado y restringe el alcance de acciones de la estrategia de salud de la familia. Se destaca el vínculo, las acciones orientadas a la comunidad y formación profesional enfocada en las nuevas necesidades del trabajo en salud, como elementos que pueden calificar el tratamiento en la atención primaria de la salud. Conclusión: A pesar de la implementación de la estrategia de salud de la familia en el municipio estudiado hace casi dos décadas, su papel reestructurador del modelo de atención todavía presenta debilidades. Los agentes del trabajo reconocen la necesidad de cambio, pero mantienen la articulación de las acciones cotidianas sin transformaciones de orden simbólicas. Hay evidencias de prácticas exitosas que incorporadas a las prácticas de atención de salud, contribuirán a la calificación de la asistencia y reemplazo del modelo de atención de salud.

Descriptores: Estrategia de Salud Familiar; Atención Primaria de Salud; Sistema Único de Salud; Tecnología Biomédica.

${ }^{1}$ Mestre em Enfermagem pela Universidade Federal de Minas Gerais. ${ }^{2}$ Doutoranda em Ciências da Saúde pela Universidade Federal de São João del-Rei. ${ }^{3}$ Mestre em Ciências da Saúde pela Universidade Federal de São João del-Rei. ${ }^{4}$ Pós-Doutora em Enfermagem, docente Adjunta IV (Enfermagem) na Universidade Federal de São João del-Rei, Campus Centro-Oeste, Divinópolis, MG. ${ }^{5}$ Doutora em Enfermagem, docente Adjunta III (Enfermagem) na Universidade Federal de São João del-Rei, Campus Centro-Oeste, Divinópolis, MG. ; Available in: DOI: 


\section{INTRODUÇÃO}

A Atenção Primária à Saúde (APS) se caracteriza por um "conjunto de ações de saúde individuais, familiares e coletivas que envolvem promoção, prevenção, proteção, diagnóstico, tratamento, reabilitação, redução de danos, cuidados paliativos e vigilância em saúde". Deve ser a preferência do sistema de saúde, atuando como ordenadora e coordenadora do cuidado, tendo essa Estratégia Saúde da Família (ESF) como prioritária, para reorientar o modelo assistencial, seguindo suas diretrizes e os princípios do Sistema Único de Saúde (SUS) ${ }^{(1-2)}$.

No atual contexto da ESF, é possível observar a reprodução de práticas assistenciais com foco na doença, a partir do modelo fragmentado de trabalho, mesmo verificando que a integralidade do cuidado é eixo condutor do processo de mudanças para a ruptura de valores tradicionais na saúde ${ }^{(3)}$. Para estabelecer práticas transformadoras, o trabalho em saúde, na APS, deve ser readequado, o que requer de trabalhadores, gestores e usuários maior capacidade de análise, intervenção e autonomia para que ações centradas em procedimentos deem lugar ao modelo de atenção com foco na singularidade dos usuários ${ }^{(4)}$.

O trabalho das equipes da ESF "deve estar pautado na implementação de atividades com prioridade para a solução dos problemas dos usuários dos serviços e em sua resolutividade com responsabilidade" ${ }^{\prime(5)}$. A capacidade de agir dos trabalhadores "está relacionada dialeticamente com o contexto da rede de serviços, com o modo de fazer a gestão, com as condições gerais de trabalho nas unidades de APS e com a sua capacidade de mobilização subjetiva a cada situação de trabalho"(5).

Com base na vivência como residente de Enfermagem na Atenção Básica e Inserção, no atual contexto da APS, tendo a ESF como campo de prática, observou-se que seu papel de reordenadora do modelo de atenção à saúde ainda é incipiente no município em estudo.

Justifica-se este trabalho pela relevância de analisar o cotidiano de trabalho na ESF e as experiências vividas, as crenças e as ações dos sujeitos nos seus ambientes de relações ${ }^{(6)}$. Assim, é preciso estar atento às 'coisas mesmas' e à sua lógica interna. Sendo assim, é necessário compreender a cultura popular que mantém uma relação mágica com seu ambiente natural, com o mundo dos objetos e com a interatividade que se estabelece com o mundo material constitutivo da vida quotidiana ${ }^{(7)}$.

Nesta conjuntura, questiona-se: como é o cotidiano de trabalho das equipes da ESF? Diante da necessidade de aprofundar esta temática e, considerando a importância da qualificação da APS, este estudo tem por objetivo analisar o cotidiano do trabalho de equipes da Estratégia Saúde da Família.

\section{MÉTODOS}

Este é um estudo de caso ${ }^{(8)}$ de abordagem qualitativa, fundamentado no Interacionismo Simbólico, que "constitui uma perspectiva teórica que possibilita a compreensão do modo como os indivíduos interpretam os objetos e as outras pessoas com as quais interagem e como tal processo de interpretação conduz o comportamento individual em situações específicas ${ }^{\prime \prime(9)}$.

O estudo foi realizado, em um município de médio porte de Minas Gerais, que, em junho de 2016, apresentava uma cobertura de ESF de $46,33 \%{ }^{(10)}$. Para definir os cenários elegíveis ao estudo, foram elencadas, para sorteio aleatório apenas as equipes da ESF, cujos profissionais médicos e enfermeiros atuavam, no mínimo, há um ano na atual unidade, tempo de vivência estimado pelas autoras como viável para criar vínculo com a equipe e com a população da área de abrangência.

A pesquisa foi realizada, em $10 \mathrm{ESF}$, sendo que o número de unidades que participaram do estudo não foi definido a priori, e a coleta de dados foi interrompida mediante a saturação de dados. Por saturação, entende-se que o pesquisador conseguiu compreender, em campo, a lógica interna do grupo em estudo ${ }^{(11)}$, portanto conseguiu obter a resposta ao seu problema de pesquisa.

Foram convidados a participarem do estudo todos os médicos, enfermeiros e técnicos de enfermagem, agentes comunitários de saúde (ACS) e os cirurgiões-dentistas das equipes de saúde bucal vinculados às ESF sorteadas. Foram excluídos do estudo os profissionais elegíveis que estavam de férias regulamentares ou licença médica.

Para a abordagem dos participantes do estudo, os pesquisadores enviaram uma cartaconvite à equipe sorteada e realizaram a abordagem face a face de cada um de seus membros. Mediante concordância para a participação no estudo e assinatura do Termo de 
Consentimento Livre e Esclarecido (TCLE), a coleta de dados ocorreu, por meio de entrevista semiestruturada, realizada por um único pesquisador, no próprio ambiente de trabalho, individualmente e em um local reservado, por meio de roteiro semiestruturado composto por questões de caracterização do entrevistado e questões acerca do cotidiano do trabalho na ESF. $O$ roteiro de coleta de dados foi submetido a um pré-teste, a fim de verificar a adequação das questões e o seu entendimento pelos entrevistados, dois enfermeiros, um ACS, um médico e um técnico de enfermagem, pertencentes a equipes de ESF não elegíveis para o estudo.

Após adequações no roteiro, as entrevistas aconteceram, no período de março a junho de 2016, com 39 profissionais, sendo 10 ACS, seis cirurgiões-dentistas, nove enfermeiros, seis médicos e oito técnicos de enfermagem. Todos os participantes autorizaram a gravação em áudio, e a duração média das entrevistas foi de 21 minutos. O diário de campo foi utilizado apenas para registrar as perdas de participantes, que foram sete recusas e quatro ausências do profissional por férias ou licença médica.

Utilizou-se a análise de conteúdo na modalidade temática, considerada apropriada para investigações qualitativas em saúde por ter como finalidade descobrir os núcleos de sentido e propiciar uma comunicação significativa ao alcance dos objetivos propostos ${ }^{(11)}$.

Para a organização dos dados, as entrevistas foram transcritas na íntegra e, para garantir o anonimato dos participantes, foram identificadas pela letra $E$ de entrevistado com o respectivo número da entrevista, seguido pela letra $C$ de cenário com o respectivo número do cenário (exemplo: E1C1, E2C1, E1C2, E2C2...). As entrevistas transcritas não foram retornadas aos participantes do estudo para correções ou comentários. Ainda na etapa de pré-análise, foi realizada a leitura flutuante das entrevistas de forma a aprofundar o conteúdo, possibilitar a codificação do material empírico e identificar unidades de registro.

Em seguida, as unidades de contexto com temas semelhantes foram organizadas em categorias empíricas: o trabalho em saúde no cotidiano das equipes da ESF; fatores facilitadores e fatores dificultadores. No entanto, como o interacionismo simbólico permite a análise da realidade empírica, numa abordagem dialética ${ }^{(9)}$, as autoras optaram por apresentar os resultados da pesquisa em um texto sem a estruturação por categorias elucidadas na análise de conteúdo temática. $\mathrm{Na}$ etapa de tratamento e interpretação dos dados, foram estabelecidas relações entre os dados encontrados e a literatura científica.

A coleta de dados se iniciou, após aprovação do projeto pelo Comitê de Ética, sob o parecer no $1.377 .807 / 2016$, CAAE 49972715.2.0000.5545, em conformidade com a regulamentação ética brasileira.

\section{RESULTADOS E DISCUSSÃO}

Do total de 39 profissionais que participaram deste estudo, 31 eram do sexo feminino. O tempo médio de experiência dos participantes, em serviços de APS, foi de 10 anos e dois meses, sendo que o tempo médio de inserção na atual ESF foi de quatro anos e 10 meses.

Dos profissionais de nível superior, 13 possuíam pós-graduação latu sensu na área de saúde da família e sete em outras áreas. O tempo de habilitação dos cenários do estudo, na modalidade de ESF, variou de um a 18 anos, com média de nove anos e 11 meses, sendo cinco ESF campos de atuação de Enfermeiros vinculados a um programa de pós-graduação latu sensu na modalidade de Residência.

$\mathrm{Na}$ primeira categoria empírica, "O trabalho em saúde no cotidiano das equipes da ESF", revela-se que o trabalho em saúde implica, primeiramente, o reconhecimento do seu objeto pelos agentes. "Cada um sabe o que faz, então (...) você não precisa mandar, todo mundo já sabe o que tem que fazer, são dezoito anos, né? Então tá todo mundo adestrado já a chegar, fazer seu serviço" (E1C3).

O trabalho em saúde tem por finalidade desenvolver atenção integral que impacte na situação de saúde e autonomia das pessoas e nos determinantes e condicionantes de saúde das coletividades $^{(1)}$. Como objeto de trabalho, é proposto o corpo humano com suas dimensões individual e coletiva, considerando o conceito ampliado de saúde. Os meios, para a realização do trabalho, são os instrumentos e o conhecimento técnico, que, utilizados pelos profissionais, geram como produto final a própria assistência à saúde ${ }^{(12)}$.

Os participantes da pesquisa identificam a "doença" como objeto principal, no cotidiano de trabalho, reproduzindo o modelo assistencial curativista. "Prevenção a gente tem pouca coisa que seriam as vacinas, é... poucos projetos de 
hipertenso, diabéticos (...) então a gente tá fazendo mais é curativo e atendimento médico de doença mesmo, sem prevenção" (E3C8). "A gente ainda trabalha neste modelo assistencialista, por mais que a gente queira, a gente ainda trabalha com um modelo "estilo postão": se eu adoecer, eu vou lá e pego uma ficha" (E1C2).

Essa constatação é justificada pela primeira premissa do Interacionismo Simbólico, que estabelece que a atuação das pessoas no mundo é fundamentada com base nos significados que este mundo lhes apresenta. E esses significados atribuídos, de acordo com a segunda premissa, são sustentados por uma duradoura ação e interação humana ${ }^{(9)}$. A atenção à saúde com foco em ações curativas mantém a divisão do trabalho centrado na atuação do médico. Os demais profissionais complementam o ato médico, ao desenvolver ações isoladas, sem integração com os demais membros da equipe e sem reconhecimento do resultado final do trabalho ${ }^{(13)}$. Por isso, não se pode desconsiderar o significado da função atribuído pelos participantes da pesquisa ao objeto de trabalho na ESF, pois ele é fundamental na formação do comportamento.

Em estudo acerca dos modelos de atenção e trabalho em saúde mostrou-se que as demandas dos usuários aos serviços de saúde refletem diretamente na escolha do objeto de trabalho dos profissionais da APS $^{(13)}$. E, para atender as necessidades de saúde da população do cenário deste estudo, os profissionais da ESF organizaram o processo de trabalho de maneira fragmentada, de acordo com as habilidades e competências de cada profissional. "Então os serviços delas [das ACS] é basicamente as visitas e as buscas ativas, né? Então é basicamente no campo. A enfermeira trabalha com puericultura e preventivo, né? Exame preventivo de colo de útero (...) ela faz triagens e ela faz os demais atendimentos junto comigo, igual, por exemplo, agora ela está fazendo vacina, me ajuda, quando eu preciso fazer uma outra coisa. Mas o serviço básico da enfermeira é, além de coordenar a unidade (...), ela é responsável pelas triagens (...) o doutor atende as consultas domiciliares, prénatal, retorno de exames e consultas de rotina (...) O dentista atende a demanda mesmo do tratamento dentário, a auxiliar, o serviço básico dela é auxiliar a dentista e, quando ela pode ela me ajuda aqui, geralmente separa ficha, guarda fichas, essas coisas (...). Eu faço vacina, ah...a enfermeira faz curativos também. Agora eu faço vacina, faço curativos, faço a pré-consulta, faço a pós-consulta, que mais? [risos]. Tudo que aparecer" (E3C1).

A divisão técnica e social do trabalho, evidenciada nesta pesquisa, tem raízes no sistema capitalista, que segrega a concepção do trabalho da sua execução propriamente dita. Outro estudo também evidenciou que a prática profissional na APS é, predominantemente fragmentada, voltada ao modelo biomédico, o qual aponta a necessidade da realização de uma prática de cuidado integral que vá além da mera execução de procedimentos e técnicas ${ }^{(4)}$.

$\mathrm{Na}$ perspectiva do Interacionismo Simbólico, o significado é produzido, a partir da interação humana ${ }^{(9)}$, e os participantes do estudo reconhecem que a organização do trabalho, baseada na demanda espontânea, contribui e reforça a reprodução do modelo médicocentrado de atenção à saúde, restringe o escopo de ações da ESF e dificulta a identificação das prioridades de saúde do território. "A gente ainda trata mais do que promove saúde, a gente age mais na doença, né? (...) pode ver até mesmo pela agenda nossa. Noventa por cento é atendimento de consulta direcionado para queixa de paciente (...) e de medicalizar o paciente. A maioria dos que vem é querendo um remédio." (E3C2). "É o processo de trabalho aqui, a gente tenta organizar de acordo com a demanda espontânea, né? A gente não conhece certinho a realidade mesmo da área de abrangência" (E2C1).

Apenas alguns entrevistados nos cenários 7, 9 e 10 citaram a utilização do Diagnóstico Local como ferramenta para o planejamento das ações de saúde. "Um diagnóstico pra levantar o que a gente já conseguiu, ter mesmo ali no gráfico o que melhorou, o que não melhorou. $E$ trabalhar em cima de metas, pra gente levantar problemas, traçar prioridades (...) você consegue trabalhar mais direcionado" (E2C7).

A situação apontada pelos participantes, referente ao predomínio da assistência, a partir da demanda espontânea, pode ser um possível resultado da falta de estruturação do trabalho em saúde, em prol das necessidades dos usuários, associada à ausência de ações programáticas efetivas. Segundo a perspectiva interacionista, os profissionais de saúde são atores que definem seus papéis e adotam apenas as ações que têm significado para eles, sendo que esse significado surge da interação com as pessoas e com o ambiente ${ }^{(9)}$. Desta forma, é necessário desenvolver um "olhar epidemiológico" sobre a população, o qual seja capaz de revelar riscos e 
problemas de saúde não percebidos ou não valorizados pelos profissionais e favorecer a oferta de serviços para além de áreas restritas e focadas no atendimento médico ${ }^{(14)}$.

Tal necessidade de desenvolvimento de habilidades e competências que favoreçam tanto o processo de trabalho quanto a expansão e consolidação da ESF foi experenciado, no cenário de estudo, conforme a fala, a seguir: "Nós fazemos uma visita domiciliar, em Cuba, promovendo, prevenindo e aqui não, aqui é só o paciente que precisa, é só um dia, só pela tarde, não dá pra fazer em todos (...) falta ainda é vivência, trabalhar só com promoção, prevenção. Estamos tratando mais que promocionando e prevenindo (...) ela [a população] procura mais para tratamento, está muito longe de procurar para prevenir" (E2C9). "O povo fala assim, ah, tinha que ter mais médico. Eu não acho que tem que ter mais médico, eu acho que tinha que ter mais profissional de saúde ao ser humano, entendeu? (...) Eu aprendi isso muito com os médicos cubanos (...) a gente vê o diferencial, porque eles realmente vão no foco da doença" (E1C2).

O Programa "Mais Médicos para o Brasil" apontou intervenções positivas, no cenário brasileiro, em virtude da formação desses profissionais ser voltada ao atendimento integral aos usuários e comunidade ${ }^{(15)}$. Outros estudos ${ }^{(16-}$ ${ }^{17)}$ também evidenciaram resultados satisfatórios deste Programa, como a melhoria do acesso e desempenho dos serviços de APS, conforme demanda dos municípios, o que sugere esses profissionais como potenciais reestruturadores das práticas de atenção na ESF.

Desde a década de 70, observa-se a busca por mudanças, na formação em saúde no Brasil, a partir de tentativas, ainda que não muito efetivas, de integração ensino-serviço. Em 2001, com a implantação das Diretrizes Curriculares Nacionais, tornou-se possível aproximar formação em saúde dos princípios do SUS, o que representou um marco na reorientação da formação em saúde por ter influências diretas do Ministério da Saúde $(\mathrm{MS})^{(18)}$.

No cenário deste estudo, o desenvolvimento de outros modos de pensar e produzir saúde ${ }^{(19)}$ foi provocado pelos enfermeiros de um programa de residência em saúde da família. "A vinda do residente facilitou muito a nossa vida (...) eu não vejo a equipe mais sem a presença de um residente (...) na verdade, são dois enfermeiros trabalhando, né? Então essa parte de prevenção, de promoção de saúde, de visita domiciliar, melhorou muito (...) a gente olha o residente que saiu, se a gente for listar no papel o diferencial que ele fez, é muito grande. Então eu acho (...) que é um fator muito positivo e muito motivador pra equipe" (E2C3).

A presença do residente, segundo o Interacionismo Simbólico, produz um novo processo interativo entre os agentes do trabalho na equipe de Saúde da Família. Assim, novas interações simbólicas são estabelecidas e constituirão o processo que resultará na mudança de comportamento ${ }^{(9)}$.

Os entrevistados das ESF, as quais são campos de atuação do Enfermeiro Residente em Saúde da Família, caracterizaram este profissional como um facilitador da organização do processo de trabalho em saúde, uma vez que ele contribui para aumentar o escopo de ações das equipes. "O residente é um parceiro muito bacana. Ele vem com outros olhares, outros saberes e que consegue desenvolver junto com a equipe algumas ações que, às vezes, estavam esquecidas, por exemplo, a saúde da mulher. 0 pré-natal é uma coisa que eu não tinha propósito de fazer. Com a chegada do residente a gente organizou e viu que dá pra fazer. Então ele é um elo entre o teórico e a prática. (...) Tem seis anos que eu estou aqui na ESF, mas, às vezes, a gente pelo corre-corre no dia a dia, a gente deixa algumas coisas de lado que são importantes, aí o residente vem com esse novo olhar, esses novos saberes e ajuda a gente a entrar no eixo de novo de acordo com a realidade da população que a gente atua, não é?" (E2C5). "O residente chega num gás, querendo mudar, melhorar, faz a gente buscar mais, estudar. Por exemplo, a gente está querendo implantar o grupo de gestante, está querendo começar a fazer pré-natal, vou começar fazer consulta de hipertensos e diabéticos que também que eu não fazia" (E1C9).

Estudo corrobora que o residente é estimulado, a todo momento, a propor e a desenvolver junto à equipe de trabalho novas atividades como consultas de enfermagem a grupos prioritários que não são comumente realizadas pelos enfermeiros, como pré-natal, consulta de hipertensos e diabéticos, de pacientes com Hanseníase e Tuberculose; implementação da sistematização da assistência de enfermagem; grupos educativos com a população e o estabelecimento de parcerias intersetoriais na área de abrangência da $\operatorname{ESF}^{(20)}$. Ou seja, à luz do Interacionismo Simbólico ${ }^{(9)}$, 
depreende-se que as atividades desenvolvidas e estimuladas pela presença do residente constituem fatores positivos à construção de novos comportamentos pelos membros da equipe de Saúde da Família.

Como é esperado que as equipes de ESF desenvolvam ações, para a prevenção de doenças e promoção da saúde, alguns entrevistados pontuaram a realização dessas ações em seu território de abrangência. "Há quatro anos a gente fundou um grupo (...) lá não tem faixa etária, nós aceitamos todos e a gente procura buscar temas que trabalhem a saúde de um modo geral. (...) nós estamos no $32 \circ$ encontro (...) a gente trata todos com igualdade e, com isso, a gente estabeleceu um vínculo (...) hoje a equipe vai toda nesse grupo (...) eu fico feliz, porque é um horário de 14 horas da tarde com chuva ou com sol eles estão lá (...). Então a população está firme e forte. Isso é gratificante" (E1C2). "A gente faz sala de espera ou a gente faz grupos específicos, de acordo com a necessidade: hipertenso, diabético, gestante, crianças, mães na puericultura, grupo de mulheres" (E2C3).

Entretanto, por questões diversas, até mesmo inerentes à própria organização do processo de trabalho das equipes, nem sempre é possível dar seguimento a essas ações. "A gente faz alguns grupos de hipertensos, diabéticos, a gente tem na unidade o grupo de tabagismo também (...) funciona um período, para, funciona, para, por causa mesmo de funcionário, por falta de organização da equipe, a gente não consegue manter isso" (E3C8)

É importante destacar, ainda, que há um reconhecimento, por parte dos entrevistados, dos atributos essenciais da APS, como o vínculo, acesso de primeiro contato e longitudinalidade; e os derivados, como a orientação para a comunidade e a competência cultural, podem ser "disparadores" de práticas orientadas pelos princípios e diretrizes da APS. Em alguns locais, consultas, grupos educativos e atividades nas escolas são realizados à noite ou aos sábados pela manhã, para atender a população que não tem disponibilidade de comparecer no horário habitual de funcionamento das unidades. "Um dos pilares da saúde da família é a longitudinalidade. Então todos são antigos aqui, então você conhece a pessoa pela voz. Você sabe tudo sobre ela (...) uma interação com a comunidade depende do tempo que você está aqui (...) Quando eu cheguei aqui eu tratava do pai e da mãe, depois passei a tratar do pai, da mãe e da filha, hoje eu já trato dos netos. Então eu acho que é um facilitador, porque eu já conheço a família em três gerações" (E1C3). "A população não sabia nem o que era conselho municipal de saúde (...) foi fruto desse trabalho em que a gente foi desenvolvendo o trabalho na comunidade e a comunidade foi conhecendo e vendo que aquilo é importante e foi apoiando" (E1C2). "Tem alguns grupos também que a gente faz, não no horário do trabalho, por exemplo, no sábado pela manhã, por exemplo, um dia pela noite, tentamos fazer na variedade da população, principalmente aqueles pacientes que no horário do dia não podem participar, então fazemos isso" (E4C2).

Em meio a tantos desafios, é relevante manter esforços, para aumentar a qualidade dos serviços de saúde, por meio da busca por diferentes estratégias e modos de atuação que objetivem "desconstruir o modo hegemônico de produzir saúde" ${ }^{\text {(14) }}$ e vão além da medicalização. O encontro com os usuários, seja nos territórios, em domicílio ou em diferentes espaços, favorece - olhar ampliado do profissional, que passa a considerá-los a partir de sua história de vida e não apenas como sujeitos a adoecimentos ${ }^{(4,14)}$.

Países da América do Norte tiveram que redesenhar seus sistemas de saúde, para reduzir as desigualdades de acesso, ampliar os serviços de saúde e satisfazer as necessidades de seus usuários. Para isso, enfatizaram o trabalho interprofissional, ampliando, sobretudo, os papéis da enfermagem. Dar autonomia ao trabalho da enfermagem mostrou-se uma estratégia poderosa na continuidade do cuidado. Foi possível ainda verificar a redução de procura por consultas médicas especializadas, pela maior adesão ao tratamento estabelecido, principalmente, das doenças crônicas não transmissíveis ${ }^{(21)}$.

A rotatividade de profissionais nas equipes, em razão de contratos temporários de trabalho, foi citada como fator dificultador do trabalho em saúde, assim como o quadro de funcionários incompleto, microáreas descobertas, ou, ainda, população sob responsabilidade da ESF que extrapola o preconizado pela Política Nacional de Atenção Básica (PNAB). "Porque como nosso contrato está acabando, não vai ser renovado (...) o que nós conseguimos agora, que nós temos assim realmente a confiança da população ela vai ser quebrada (...) Então quem chegar, vai ter que construir todo o caminho de novo. Tudo que nós fizemos vai ter que ser refeito" (E2C2). "É uma 
ESF desorganizada, não só pela equipe (...) mal formada, não é? A gente deveria ter todos os ACS, a área cadastrada a gente não tem, a ESF nossa tem dois agentes comunitários, deveria ter cinco, não conhecemos nossa população" (E3C8).

A Gestão do município se encontra distante da realidade do trabalho desenvolvido pelos profissionais nas equipes de ESF, valoriza a produtividade, em detrimento da qualidade dos serviços (E1C5), o que corrobora com a prática do modelo de atenção médico-centrado. "Já que nós estamos falando da ESF e atenção primária, ressaltar assim que os gestores, né? Na minha avaliação, é o pessoal da secretaria de saúde poderia ter um diálogo maior com as unidades. De atenção para ver como que é cada realidade específica, das unidades e, na verdade, isso não existe" (E1C1). "Mas o que está acontecendo mesmo, não tem ESF não, é um postão! (...) Nem um carro pra fazer visita domiciliar a gente tem" (E1C4).

Os discursos permitem evidenciar que o modelo de atenção, assumido pelo município, tem impactado no modo como os participantes significam aspectos do cotidiano que tocam negativamente o processo de trabalho da equipe. Isso pode ser compreendido à luz do referencial teórico adotado, no presente estudo, o qual afirma que os significados são formados e transformados positiva ou negativamente no processo de interação humana ${ }^{(9)}$.

Deve-se considerar que o estabelecimento de vínculo entre profissional e usuário, por meio de relações de confiança e corresponsabilização, permite o desenvolvimento de atenção usuáriocentrada e colabora com o desenvolvimento de novos modos de produzir saúde ${ }^{(13)}$. O vínculo, portanto se configura como tecnologia leve que possibilita construções que geram impactos positivos aos problemas de saúde dos usuários ${ }^{(11)}$.

Vale ressaltar, ainda, que o conhecimento deficiente da população sobre o que é ESF, seus objetivos e sua finalidade, dificultam a organização do trabalho, principalmente, nas equipes recentemente habilitadas na ESF. "Nós estamos aí com dificuldades com a população, por causa que a gente tinha dois ginecologistas e hoje não tem mais, por conta dos critérios da estratégia (...) a população não aceita" (E1C4). "Até hoje ele foca muito na pessoa do médico (...) complicado de trabalhar prevenção em uma comunidade que até então só pensava em curativo" (E1C5)
Dessa forma, diante do cuidado em saúde focado em ações curativas, os participantes apontam que a ESF não cumpriu seu papel de reorganizadora do atual modelo assistencial e funciona como unidade tradicional, popularmente conhecida como "posto de saúde": "A ESF não deixou de ser um postão, uma unidade básica, porque a nossa população aqui, infelizmente, a característica dela é muito de receita (...) muito medicamento, então essa parte da promoção, da prevenção, de trabalhar informação em saúde, ESF mesmo que é o cuidado todo do familiar, no contexto geral, ainda nós temos que trabalhar muito pra melhorar isso" (E1C4).

Os profissionais reproduzem o modelo de atenção à saúde, "estilo postão" (E1C2), uma vez que reconhecem que não há direcionamento pessoal e/ou coletivo para a reorganização do trabalho em saúde. Esse fato também ocorre porque estão "adestrados já a chegar, fazer seu serviço" (E1C3). No entanto os participantes reconhecem a necessidade da educação permanente em saúde: "Eu acho que a gente precisa, a minha formação eu não tive muita ênfase nessa questão da organização do processo de trabalho. Eu acho que falta conhecimento, eu acho que é isso (...)" (E1C9). "Eu acho que assim, o que poderia melhorar também no processo de trabalho seria talvez alguma educação permanente, que acho que tem hora que falta um pouquinho, não é? Que tenha alguma coisa para capacitar a gente também, para estar atuando de acordo com aqueles problemas visíveis que a gente tem. Acho que isso poderia melhorar também um pouco" (E2C1).

Neste contexto, é possível inferir que a formação de recursos humanos, voltados para o SUS e o trabalho em equipe são elementos que podem qualificar o atendimento na APS. A qualificação profissional constitui ferramenta importante, a fim de reestruturar o modelo de atenção, quanto à necessidade de restaurar práticas assistenciais assertivas que possibilitem o reconhecimento e atuação efetiva sobre as condições de saúde e seus determinantes ${ }^{(13,22)}$.

Em países que apresentam avanços no cuidado primário em saúde, como o Canadá, onde há busca pelo fortalecimento da atenção primária e enfoque comunitário na assistência à saúde, há evidências de que a atuação interdisciplinar e o trabalho em equipe favorecem a qualidade do serviço ${ }^{(23)}$. 
Decorrente de tais considerações, o Interacionismo Simbólico permitiu conhecer a complexidade e a ambiguidade dos significados atribuídos pelos atores envolvidos no cotidiano de trabalho da equipe de Saúde da Família. O atual desafio da ESF é reestruturar o trabalho das equipes na perspectiva de construir um novo modelo de atenção à saúde. Desta forma, a organização, o planejamento dos serviços e o preparo profissional são prioridades para alcançar tais objetivos ${ }^{(24)}$. Conforme demonstrado nas falas dos entrevistados, cada localidade apresenta sua realidade e necessidade de saúde, o que demanda diferentes formas de organizar o trabalho, para impactar em melhorias das condições de saúde dos usuários.

Assim sendo, é relevante destacar que, em meio a um contexto que reproduz técnicas tradicionais de atenção à saúde, com foco no modelo biomédico, ainda surgem profissionais que reconhecem o real significado da APS e tentam expressar tal significado em suas práticas. "Estratégia Saúde da Família é o primeiro contato que a pessoa tem com o sistema de saúde, é a atenção primária (...). É mais importante prevenir que ter que curar e a prevenção que tá diretamente relacionada com a atenção primária em saúde (...). A finalidade do meu trabalho é a prevenção e promoção de saúde. Eu acho que a finalidade de toda atenção primária. A parte curativa também (...), porque a atenção primária inclui tudo. Estou falando que o mais importante da atenção primária é a prevenção e a promoção, embora você faça o curativo, faça tudo o que tem que fazer" (E1C10).

Pesquisadores afirmam que o modelo de atenção à saúde corresponde à forma como as tecnologias e saberes são organizados em um sistema para responder às necessidades de saúde da população ${ }^{(13)}$. As experiências exitosas evidenciadas, no cenário deste estudo, apontam a necessidade de desenvolver ações com foco na integralidade do cuidado. O trabalho em saúde deverá ser realizado em equipe, por meio da complementaridade das ações e circulação entre saberes, pois, atuando em conjunto, os atores deste processo constroem o caminho a ser seguido com base nas políticas e pressupostos que norteiam a ESF e o SUS ${ }^{(3)}$. Entretanto o trabalho em saúde nem sempre funciona, baseado apenas em normas e diretrizes, visto que trabalhadores e, até mesmo o próprio cotidiano de trabalho, requerem constantes reinterpretações e reinvenções no modo de produzir saúde ${ }^{(25)}$. Segundo a terceira premissa do Interacionismo Simbólico, é por meio das interações humanas que os significados das ações podem ser mantidas ou modificadas pelos indivíduos ${ }^{(9)}$.

Nesta perspectiva, os trabalhadores protagonistas do processo de mudança do trabalho em saúde deverão receber qualificação permanente, para que, a partir do diálogo com usuários dos serviços e com a própria equipe de trabalho, ancorados em uma reflexão crítica sobre suas ações, possam reconhecer as dificuldades no cotidiano dos serviços e incorporar práticas efetivas para qualificação da assistência à saúde ${ }^{(26-27)}$.

\section{CONSIDERAÇÕES FINAIS}

Após mais de duas décadas de implantação da ESF, no Brasil e quase duas décadas, no município de estudo, o seu papel de reestruturadora do modelo de atenção ainda apresenta fragilidades. A necessidade de mudança é reconhecida pelos atores do trabalho, mas eles mantêm articulação das ações cotidianas sem mudanças de ordens simbólicas. Houve evidências de práticas e experiências exitosas, centradas no usuário e em suas necessidades, que podem ser consideradas situações capazes de modificar os significados do trabalho cotidiano na APS e, assim, reorganizar o trabalho das equipes.

Todavia fatores como predomínio do modelo curativista, ações de saúde fragmentadas e voltadas para demanda espontânea, alta rotatividade dos profissionais e desconhecimento da população sobre ESF são reconhecidos como entraves para os avanços na atenção à saúde. Tais pontos devem ser discutidos, reduzidos ou modificados, a fim de que se alcance o objetivo final da APS: qualificação da assistência à saúde e melhoria da qualidade de vida dos usuários.

Constatou-se a importância da formação profissional voltada, para a ruptura de práticas centradas no modelo biomédico, em especial, ao programa de Residência em Enfermagem, que tem por premissas fortalecer e consubstanciar a implementação do SUS como política de saúde, por meio da articulação entre o mundo do trabalho e da educação e, assim, formar profissionais capazes de realizar uma assistência de qualidade baseada nos princípios e diretrizes desse Sistema.

Dessa forma, conforme evidenciado neste estudo, a presença do Residente de Enfermagem, 
no cotidiano de trabalho das equipes, aproxima o real do ideal, pois, além de impulsionar a equipe a almejar a construção de práticas coerentes com a proposta reestruturante da ESF, constitui-se também como força de trabalho, para operar tais mudanças e enfrentar o modelo biomédico, ainda tão cristalizado nas práticas em saúde da APS.

É reconhecido que não há fórmula adequada do caminho a ser seguido - talvez seja esse o fator que mais favorece a falta de organização do trabalho pelas equipes, gerando diferentes configurações do trabalho cotidiano. Neste sentido, ressalta-se a importância de estudos acerca de práticas exitosas, para a organização do trabalho na ESF e, também, sobre aquelas que dificultam este processo, para que seja possível alcançar o objetivo proposto que é a construção de um novo modo de produzir saúde.

Como limitações deste estudo, indica-se sua realização em um município que apresente cobertura de ESF em torno de $40 \%$, o que sugere dificuldades da gestão municipal em implementar a política de reorganização da APS. Sendo assim, acredita-se que as recusas de participação no estudo não impactariam a realidade empírica, evidenciada pelos profissionais e, desta forma, demonstra=-se que ele traz contribuições à prática da enfermagem e dos demais profissionais da saúde.

\section{REFERÊNCIAS}

1. Brasil, Ministério da Saúde. Portaria no 2436, de 21 de setembro de 2017. Aprova a Política Nacional de Atenção Básica, estabelecendo a revisão de diretrizes para a organização da Atenção Básica, no âmbito do Sistema Único de Saúde (SUS). Diário Oficial da União 2017.

2. Souza CR, Botazzo C. Construção social da demanda em saúde. Physis 2013;23(2):393-413. DOI: $10.1590 /$ S0103-73312013000200005

3. Viegas SMF, Penna CMM. As dimensões da integralidade no cuidado em saúde no cotidiano da Estratégia Saúde da Família no Vale do Jequitinhonha, MG, Brasil. Interface 2015;19(55):1089-1100. DOI: 10.1590/1807$\underline{57622014.0275}$

4. Santos FPA, Acioli $S$, Rodrigues VP, Machado JC, Souza MS, Couto TA. Nurse care practices in the Family Health Strategy. Rev. Bras. Enferm. 2016;69(6):1124-31. DOI: 10.1590/00347167-2016-0273

5. Castro MM, Oliveira SS. Avaliação do trabalho na Atenção Primária à Saúde do município do Rio de Janeiro: Uma abordagem em saúde do trabalhador. Saúde Debate 2017;41(nesp 2):152-64. DOI: 10.1590/0103$11042017 \mathrm{~s} 213$

6. Maffesoli M. O conhecimento comum: Compêndio de sociologia compreensiva. São Paulo: Brasiliense; 2010.

7. Maffesoli M. O ritmo da vida: Variações sobre o imaginário moderno. Rio de Janeiro: Record; 2007.

8. Yin RK. Estudo de caso: Planejamento e métodos. 5a ed. Porto Alegre: Bookman; 2015.

9. Carvalho VD, Borges LO, Rêgo DP. Interacionismo simbólico: Origens, pressupostos e contribuições aos estudos em psicologia social. Psicol Ciênc Prof. 2010;30(1):146-61. DOI: 10.1590/S1414-98932010000100011

10. Brasil, Ministério da Saúde. E-Gestor atenção básica. Brasília: Ministério da Saúde; 2019 [citado em 4 set 2019]. Disponível em: https://egestorab.saude.gov.br/paginas/acessoPu blico/relatorios/relHistoricoCobertura.xhtml

11. Minayo MCS. O desafio do conhecimento: Pesquisa qualitativa em saúde. 13a ed. São Paulo: Hucitec; 2013.

12. Almeida LR, Silva ATMC, Machado LS. O objeto, a finalidade e os instrumentos do processo de trabalho em saúde na atenção à violência de gênero em um serviço de atenção básica. Interface 2014;18(48):47-60. DOI: 10.1590/1807-57622014.0560

13. Santos DS, Martins MS, Merhy EE. Processo de trabalho na estratégia de saúde da família: Potencialidades da subjetividade do cuidado para reconfiguração do modelo de atenção. Ciênc. Saúde Coletiva 2018;23(3):86170. DOI: $10.1590 / 1413-81232018233.03102016$

14. Feuerwerker LCM, organizador. Micropolítica e saúde: Produção do cuidado, gestão e formação. Porto Alegre: Rede UNIDA; 2014.

15. Kemper ES, Mendonça AV, Sousa MF. The Mais Médicos (More Doctors) Program: panorama of the scientific output. Ciênc Saúde Coletiva 2016;21(9):2785-96. DOI: 10.1590/1413$\underline{81232015219.17842016}$

16. Miranda GMD, Mendes ACG, Silva ALA, Santos Neto PM. A ampliação das equipes de saúde da família e o Programa Mais Médicos nos municípios brasileiros. Trab Educ Saúde 2017;15(1):131-45. DOI: 10.1590/1981-7746sol00051.

17. Oliveira FP, Vanni T, Pinto HA, Santos JTR, Figueiredo AM, Araújo SQ, et al. "Mais Médicos": 
A Brazilian Program in an international perspective. Interface 2015;19(54):623-34. DOI: 10.1590/1807-57622014.1142

18. Feuerwerker LCM, Capozzolo AA. Mudanças na formação dos profissionais de saúde: Alguns referenciais de partida do eixo trabalho em saúde. In: Capozzolo AA, Casetto SJ, Hens AO, organizadores. Clínica comum: Itinerários de uma formação em saúde. São Paulo: Hucitec; 2013.

19. Silva $\mathrm{CT}$, Terra MG, Kruse MHL, Camponogara S, Xavier MS. Residência multiprofissional como espaço intercessor para a educação permanente em saúde. Texto ContextoEnferm. 2016;25(1):1-9. DOI: 10.1590/01040707201600002760014

20. Ramos TM, Rennó HMS. Formação na residência de enfermagem na Atenção Básica/Saúde da Família sob a ótica dos egressos. Rev Gaúcha Enferm. 2018;39:1-9. DOI: 10.1590/1983-1447.2018.2018-0017

21. Malham AS, Touati N, Maillet L, Gaboury I, Loignon C, Breton M. What are the factors influencing implementation of advanced access in family medicine units? A cross-case comparison of four early adopters in Quebec. Int J Family Med. 2017; 2017:1-15. DOI: $\underline{10.1155 / 2017 / 1595406}$

22. Ramos CFV, Araruna RC, Lima CMF, Santana CLA, Tanaka LH. Education practices: Research-action with nurses of Family Health Strategy. Rev Bras Enferm. 2018;71(3):1144-51. DOI: 10.1590/0034-7167-2017-0284

23. Faria LR, Alvez CA. O cuidado na atenção primária à saúde: Preliminares de um estudo comparativo Brasil/Canadá. Saúde Soc. 2015;24(1):72-85. DOI: 10.1590/S010412902015000100006

24. Ferreira AL, Magalhães ACF, Corrêa LP, Rodrigues MC, Viegas SMF. A aplicabilidade dos indicadores de saúde no contexto da Atenção Primária à Saúde. Rev APS 2014 [citado em 4 set 2019]; 17(2):134-42. Disponível em: https://aps.ufjf.emnuvens.com.br/aps/article/vie w/1968/796

25. Agonigi RC, Carvalho SM, Freire MAM, Gonçalves LF. A produção do cuidado no cotidiano das Equipes de Saúde da Família. Rer. Bras. Enferm. 2018;71(Suppl 6):2659-65. DOI: 10.1590/0034-7167-2017-0595

26. Cunha AZS, Rezende MS, Weigelt LD, Krug SBF, Feil Al. Implicações da educação permanente no processo de trabalho em saúde. Espaço Saúde
2014;15(4):64-75. DOI: $\quad \underline{10.22421 / 1517-}$ 7130.2014v15n4p64

27. Bomfim ES, Oliveira BG, Rosa RS, Almeida MVG, Silva SS, Araujo IB. Educação permanente no cotidiano das equipes de saúde da família: utopia, intenção ou realidade? J. Res. Fundam. Care. 2017;9(2):526-35. DOI: 10.9789/21755361.2017.v9i2.526-535

Nota: Texto extraído do trabalho de conclusão de curso - 0 cotidiano do trabalho em equipes da Estratégia Saúde da Família: entre o real e o ideal", apresentado ao Programa de Pós-Graduação latu-sensu: Residência em Enfermagem na Atenção Básica/ Saúde da Família da Universidade Federal de São João del Rei, em 2017.

Recebido em: 18/06/2019

Aprovado em: 18/11/2019

\section{Endereço de correspondência:}

Fernanda Moura Lanza

Rua Sebastião Gonçalves Coelho, 400, Chanadour

CEP: 35501-296 - Divinópolis/MG - Brasil

E-mail: $\underline{\text { fernandalanza@ufsj.edu.br }}$ 